\title{
Online Collaborative Learning via Astronomy Online Lab: A Cross-cultural Communicative Experience for Malaysian and UK Students
}

\author{
Marlia Puteh $^{1, *}$, Shahirah Abu Bakar ${ }^{2}$, Ayu Rita Mohamad ${ }^{1,3}$, Lili Zahra Ramly ${ }^{1,4}$, \\ Nurhasmiza Abu Hasan Sazalli ${ }^{1}$, Othman Zainon ${ }^{5}$, Nilam Nur Amir Sjarif ${ }^{6}$, \\ Nurul Shazana Abdul Hamid ${ }^{7}$, Effie Law-Chong Lai $^{8}$, Nigel Bannister ${ }^{9}$ \\ ${ }^{1}$ Language Academy, Faculty of Social Sciences and Humanities, Universiti Teknologi Malaysia, Malaysia \\ ${ }^{2}$ Research Management Centre, Universiti Teknologi Malaysia, Malaysia \\ ${ }^{3}$ Department of Language Education, Faculty of Education and Social Sciences, Universiti Selangor, Malaysia \\ ${ }^{4}$ School of Education and Humanities, Universiti Tun Abdul Razak, Malaysia \\ ${ }^{5}$ Department of Geoinformation, Faculty of Built Environment \& Surveying, Universiti Teknologi Malaysia, Malaysia \\ ${ }^{6}$ Department of Advanced Informatics, Razak Faculty of Technology and Informatics, Universiti Teknologi Malaysia, Malaysia \\ ${ }^{7}$ Department of Applied Physics, Faculty of Science and Technology, Universiti Kebangsaan Malaysia, Malaysia \\ ${ }^{8}$ Department of Computer Science, University of Leicester, United Kingdom \\ ${ }^{9}$ Department of Physics \& Astronomy, University of Leicester, United Kingdom
}

Received June 24, 2020; Revised October 1, 2020; Accepted November 7, 2020

\section{Cite This Paper in the following Citation Styles}

(a): [1] Marlia Puteh, Shahirah Abu Bakar, Ayu Rita Mohamad, Lili Zahra Ramly, Nurhasmiza Abu Hasan Sazalli, Othman Zainon, Nilam Nur Amir Sjarif, Nurul Shazana Abdul Hamid, Effie Law-Chong Lai, Nigel Bannister , "Online Collaborative Learning via Astronomy Online Lab: A Cross-cultural Communicative Experience for Malaysian and UK Students," Universal Journal of Educational Research, Vol. 8, No. 11C, pp. 45 - 54, 2020. DOI: 10.13189/ujer.2020.082306.

(b): Marlia Puteh, Shahirah Abu Bakar, Ayu Rita Mohamad, Lili Zahra Ramly, Nurhasmiza Abu Hasan Sazalli, Othman Zainon, Nilam Nur Amir Sjarif, Nurul Shazana Abdul Hamid, Effie Law-Chong Lai, Nigel Bannister (2020). Online Collaborative Learning via Astronomy Online Lab: A Cross-cultural Communicative Experience for Malaysian and UK Students. Universal Journal of Educational Research, 8(11C), 45 - 54. DOI: 10.13189/ujer.2020.082306.

Copyright@2020 by authors, all rights reserved. Authors agree that this article remains permanently open access under the terms of the Creative Commons Attribution License 4.0 International License

\begin{abstract}
Communication poses several problems, particularly to English second language (ESL) learners. In overcoming these problems, some ESL learners employ communicative strategies. This study reports the efforts undertaken by Malaysian ESL learners in enhancing their communication with the native speakers during collaborative cross-cultural online activities through Astronomy Online Lab (AOL). This AOL module was utilized to achieve twofold objectives namely enhancing students' communication skills and promoting knowledge exchange during the live discussions. 29 undergraduate students from a Malaysian public university and a UK university explored the Astronomy topics online and experienced the simulation during the two live sessions conducted for one month. Data were collected from a face-to-face interview with all the Malaysian students. The
\end{abstract}

students' expectations before the live sessions, difficulties confronted when communicating with the native speakers, the communicative strategies and experience during the interactive activities were explored. The findings revealed that conversational issues such as the native's accent and the challenge in formulating strategies for solving communication problems during the conversations posed difficulties to the students. A general pattern of indirect and interactional communicative strategies as promoted by Dörnyei and Scott (1997) was evident during the interactions.

Keywords Collaborative Learning, Astronomy Online Labs, Online Platform, Communication Strategies, ESL Learners, Cross-cultural Activities 


\section{Introduction}

A communicative strategy is a significant element in second language learning. Larry Selinker, a prominent linguist who coined the term 'interlanguage' acknowledged communication strategy as one of the major undertakings involved in second language learning (Selinker, 1972). A communicative strategy is defined as "a systematic technique employed by a speaker to express his [or her] meaning when faced with some difficulty" (Corder, 1981: 103). Such definition tallied Tarone's (1980:419) who denoted communicative strategy as "a mutual attempt of two interlocutors to agree on meaning in situations where requisite meaning structures do not seem to be shared".

In Malaysia, the second language learners (ESL) perceive English as a challenging communicative skill to master (Shumin, 2002). This is because when communicating, the ESL learners feel that they are required to have proper linguistic, sociolinguistic and rhetorical competencies (Nunan \& Bailey, 2009; Mukminin et al., 2015). English is a compulsory subject to pass for students who sit for the national examination known as the Malaysian Certificate of Examination (SPM). SPM is equivalent to the General Certificate of Secondary Education (GCSE) in the United Kingdom. Not only that, students pursuing their undergraduate degree in Malaysian public higher learning institutions are also required to undertake the Malaysian University English Test (MUET) - a compulsory test to be taken during their pre-university programs, for enrolment into undergraduate courses. Despite learning English from as young as seven years old in Malaysia, many Malaysians still have difficulties in processing and expressing themselves in English. The possible reason behind the lack of English language proficiency is that it requires complex skills, beyond the understanding of grammatical and semantic rules (Abrar et al., 2018). Such difficulties are intensified by learners' lack of understanding of the meaning in multiple contexts or situations. In this regard, communicative strategies are the answer to the problem. ESL speakers expect themselves to be able to demonstrate minimal proficiency through their vocabulary, grammar, and sociolinguistics abilities when communicating with native speakers.

Communicative strategies became popular in the 1980s when Canale and Swain (1980) introduced the term 'strategic competence' - one of the important elements in their communicative competence model. Strategic competence was defined by the authors (1980: 30) as comprising “...verbal and non-verbal communication strategies that may be called into action to compensate for breakdowns in communication due to performance variables or to insufficient competence.” Dörnyei and Scott (1997) further spelled out the term 'strategy' to include a conscious technique used to achieve a goal during communication.
When confronted with problems during communication, Faerch and Kasper (1980) claimed that language users employed two types of strategies in solving the communication problem; 1) avoidance behavior - users solve the communication problem by changing the communication goal or 2) achievement behavior - users develop an alternative plan in tackling the communication problem. Faerch and Kasper (1984) further elaborated that it is common for language users to confront communication problems that require the activation of a particular strategic communicative plan as the solution. Similarly, Dörnyei and Scott (1997) introduced a taxonomy of communicative strategies which was attributed to problem management in communication. The taxonomy comprises three major categories namely direct strategies, indirect strategies, and interactional strategies. Direct strategies present alternative meaning structures to the ESL learners; indirect strategies facilitate the message to be conveyed; interactional strategies involve learners' approach to fixing the problem. Examples of direct strategies are message abandonment, message reduction, message replacement, circumlocution, approximation, literal translation, code-switching, omission, mime, and self-rephrasing. On the contrary, indirect strategies are not meaning-related through the usage of fillers, repetitions and verbal strategy markers. Interactional strategies promote successful communicative methods by engaging in appeals for help, own comprehension check, asking for repetition and clarification, guessing and expressing misunderstanding.

Such taxonomy was reported by Romadlon (2016) who studied three Indonesian students' strategies when communicating with an American. He recorded 306 turns and listed multiple strategies adopted during the one-hour conversation; circumlocution (38.98\%), language switch (15.3\%), topic avoidance (14.6\%), literal translation (6.8\%), mime (8.5\%), word coinage and message abandonment (6.8\%), appeal for assistance $(5.6 \%)$ and approximation (3.39\%). The communicative strategies were adopted when the Indonesian students identified deficiency in meaning, cultural differences, speech, voice, and fluency issues.

On a similar front, Wang et. al (2017) revealed that there was a communication breakdown between the Americans and the non-native students studying in the United States. Such breakdown related to each other's perceptions and their decision to interact. The non-native students identified their concerns in communicating with the Americans which include the perceived causes of their concerns, and the strategies they would employ to address these concerns. These communication concerns were social-psychological related, cultural-related and language-related. The non-native students applied the avoidance, interaction and self-improve English language skills strategies in dealing with their communicative concerns. It was an interesting study that revealed 
non-native students' avoidance in continuing conversations with the Americans if he/she sensed a bias perception. The Americans, on the contrary, perceived that non-native speakers with heavy and mild accents as more intelligent, more educated, and even expressed more interest in engaging in social interactions with them.

This highlights the importance of communicative strategies in solving communication problems confronted by ESL learners. These strategies help ESL learners to be autonomous in constructing self-strategy and solving communication problems to enhance their English language proficiency. The present paper aims to investigate an interesting topic on how ESL learners strategize their communication when communicating with native speakers. Three questions define the following sections;

1) What were the students' expectations before the collaborative activities?

2) What were the strategies adopted by the students when communicating with native speakers during the collaborative activities?

3) What was the students' experience after the collaborative activities?

This research involves Malaysian undergraduate students and their communication exchanges with native English speakers in a cross-cultural collaborative online learning platform. A majority of these first-year students never established direct contacts with native English speakers nor visited countries where English is the mother tongue. This study was conducted to analyze the expectations and strategies undertaken by Malaysian students during the collaborative learning activities with native English speakers.

\section{Collaborative Learning via Astronomy Online Lab}

Online learning has become an interesting tool for learning activities. The Astronomy online labs (AOL) module was designed to expose Malaysian and UK students to computer-supported audio and visual communications via the BigBlueButton (BBB) software. The objectives of the project were twofold; to enhance the students' communication skills and to promote knowledge exchange during the live discussions. Astronomy was chosen as a part of this research since it is a special branch of Science, Technology, Engineering and Mathematics disciplines (STEM) that pushes the boundaries of science and technology, while promoting economic and social development.

Through the AOL module, learners were engaged in a common task where each individual depended on and was accountable to each other. Students participated in a small group, so that every student could maximize their learning skills with the help of their peers. It is a process of sharing knowledge between two or more interacting individuals, to share the understanding of a concept, area or discipline of practice that none previously possessed or could have come across themselves. This is a constructivist educational approach involving groups of students working together to solve problems, complete tasks or generate products (Kumi-Yeboah et al., 2017). According to Baruah \& Paulus (2018), cultural differences in advancing creative endeavors may complicate the collaborative creative process. Interestingly, this study involves cross-cultural collaborative activities and the claim made by Baruah \& Paulus (2018) warrants further investigation, which unfortunately is beyond the scope of this paper.

Online collaborations promote significant benefits in respect to theoretical underpinning (knowledge building); environmental opportunities (ICT opportunities and mix of media) and constraints (ICT uptake constrained by environment); approaches (rewards and structures including PBL); benefits (fit with information society and $21^{\text {st }}$-century skills): and methods of evaluation (mix of approaches) (Hammond, 2017). Such advantages offered by online collaborative exercise were earlier deliberated by Yang et al. (2014) who classified the five key elements of collaborative learning into students' interdependence, individual accountability, online interaction opportunities, social skills development, and group work completion.

Why do we engage students in collaborative learning? Haythornthwaite (2019:10) characterized collaborative learning as fostering "active construction of knowledge, enhanced problem articulation, and benefits in exploring and sharing information and knowledge gained from peer-to-peer communication." Collaborative learning allows students to construct their knowledge by becoming autonomous learners through active teamwork activities. The activities emphasized the sense of "togetherness" which can be transformed into learning from individual contributions to group work activities (Teng, 2007).

Despite the advantages, there are several challenges of collaborative learning through online platforms. Hadwin, Bakhtiar \& Miller (2018) listed five categories of challenges faced by groups across a variety of settings namely motivational, socio-emotional, cognitive, metacognitive, and environmental challenges. Motivational challenges relate to an individual's goals and participation in the group; socio-emotional challenges promote positive vibes relating to communication and relationship in the group; cognitive challenges highlight issues in performing the shared tasks; metacognitive challenges involve problems in overseeing group's undertakings and development; and environmental challenges revolve around external conditions such as technology, resources, task complexity, etc.

Collaborative activities are very much dependent on the group members and the formation of the group. Olivera et.al. (2011) reported the distinctive characteristics of a successful and less successful group. Successful groups demonstrate a clear focus, practice collaborative work, 
define work responsibilities, reflect over outcomes, establish the final output, outline assessment requirements and revise the work. These patterns elaborate on the collaborative nature of the group. The less successful group, on the contrary, shows patterns of struggle, manifest undecisive directions, indicate lack of cooperation, display multiple views of experts and demonstrate anxiety towards the outcomes. Such patterns indicate a lack of trust and difficulties in developing group harmony.

Garrison (2019) maps the impact of the difficulties in completing tasks on the performance of a group. He addressed the gap by promoting the principles of online collaboration. Those principles were primarily aimed at engaging the students in an online learning environment and creating a community of inquiry. The community of inquiry provides support and connection, framed towards promoting students to collaboratively construct meaningful knowledge in achieving the learning outcomes. This community of inquiry is outlined by its social, cognitive and teaching presence. Social presence looks into the students' personal ability to connect with the community, cognitive presence demonstrates the students' process of knowledge construction via collaborative inquiry whereas teaching presence identifies the pedagogical elements which promote the collaborative process.

Nevertheless, the process of collaborative online learning certainly requires practice and takes time to be developed. The AOL project addresses a timely and impactful goal that was officially developmental assistance compliant. It has a strong commitment towards supporting capacity building in young adults in Malaysia for their data analysis skills and key $21^{\text {st }}$-century competencies such as communication, collaboration, creativity, and critical thinking through collaborative learning activities enabled by technologically and pedagogically sound AOL. It involves selected undergraduate students in Malaysia and the UK.

\section{Methodology}

The data was obtained from Malaysian students' communication via an Astronomy online project with native speakers from a UK-based university. Two 2-hour live sessions were conducted for such purpose. 15 undergraduate Physics students from a Malaysian public university who studied Astronomy as an elective subject participated in the research. This study explored the students' feelings before the communication with native speakers as well as the obstacles faced and the strategies utilized by them during the AOL collaborative learning activities.

Data were collected through face-to-face interviews where a series of semi-structured interview questions were conducted to elicit the participants' responses. The interview was audio-taped and lasted between 30 to 40 minutes for each participant. Data were also collected through reflective writing via WordPress, a microblogging platform. Participants were briefed about the procedures of the collaborative learning project, and interactions with them were carried out before the live sessions. This act as a pre-introduction to the project as well as a demonstration session of technological tools using the BBB software and WordPress. Students were given a series of reflective questions consisting of challenges anticipated before the collaborative activities. After the live sessions, another interview session was conducted to explore the strategies adopted by the participants during the collaborative activities, and their experiences after.

Participants' responses were qualitatively analyzed to obtain useful insights regarding the challenges during the live sessions, strategies applied in communicating with the native speakers, and their feelings before and after participating in the live sessions. A qualitative software, NVivo 12, was employed in organizing and analyzing the data as proposed by Miles and Huberman (1994) and Braun and Clarke (2006). The data coding was carried out using thematic analysis - an analytic method for identifying, analyzing and reporting patterns within data. NVivo software was selected because it enhanced the validity of the analyzed data (Singh, 2016).

\section{Findings and Discussions}

In this section, each of the research questions will be addressed. Four themes were identified from the interview data. The themes were namely 1 ) expectations before the collaborative online activities; 2) difficulties experienced during the live sessions; 3) strategies adopted when communicating with native English speakers; and 4) experience after the collaborative online activities.

\section{Expectations Before the Collaborative Online Activities}

The respondents' feelings before the live sessions were analyzed and illustrated in Figure 1. 


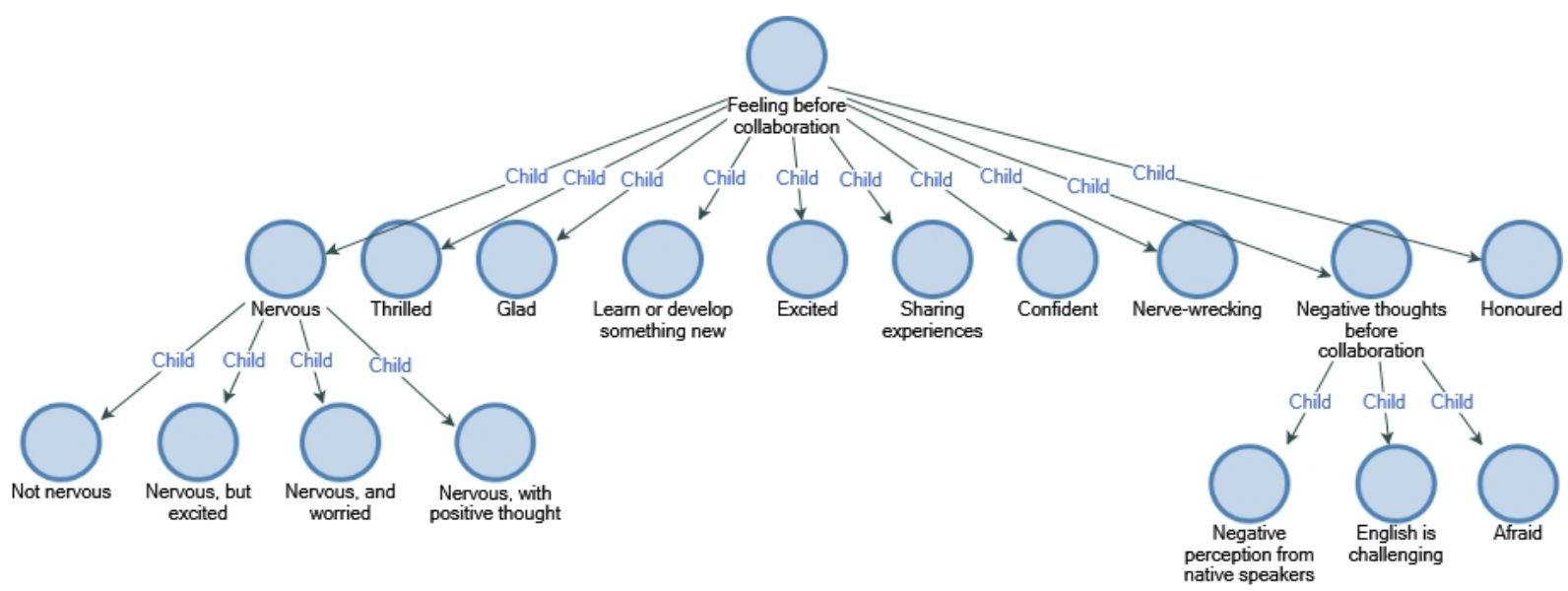

Figure 1. Feelings before the live sessions

A number of the participants were thrilled about the opportunities to participate in the project as expressed by the participants below;

"I am very excited to know what is the benefit if I joined this project and how this project can go far." (R9)

Participant R5 revealed that it was a dream-come-true to be able to collaborate with the UK students, while R9 claimed that it was a new experience to participate in an international project. She also anticipated many benefits she would gain during the collaborative activities. Several of the respondents highlighted the positive impact of the project on them as individuals. One participant, R7 expected the project to help increase his self-confidence and improve his communication skills. Meanwhile, participant R9 stated that the English language did not pose a huge challenge for her and she would be able to understand the native speakers. Her positive vibes tallied with participant R3 who explained the networking and cultural advantages posed by the project:

"I can see that this project will be a great platform for us to expand our networking. I also believe that this project will help me to see the world from a wider perspective because the collaboration between students from two different countries that are culturally and geographically different, will encourage us to understand the different cultures in a better way." (R3)
However, several respondents nursed negative feelings before collaborative activities;

"Knowing that I will be collaborating with students from the UK, I am thrilled and anxious at the same time.” (R1)

"I never had a chance to working with anyone who is from overseas countries until I came to this University. Furthermore, communicating in English will be so much challenging to me.” (R2)

"I thought they would look down on us and make me feel not confident before the live session.” (R4)

"It is not easy for us to communicate with the people who are not using our lingua franca as the base of communication, so for me, it is a great experience to take part.” (R5)

"At first I feel very confident to speak with them because before this I am doing part-time as an English teacher. But, later on, I remember that every country has its own slang in speaking English, so this may be a bit challenging for me.” (R6)

\section{Difficulties Experienced during the Live Sessions}

Respondents confronted several difficulties during the live sessions namely conversational issues and technical issues, to name a few. Figure 2 illustrates the students' difficulties during the live sessions. 


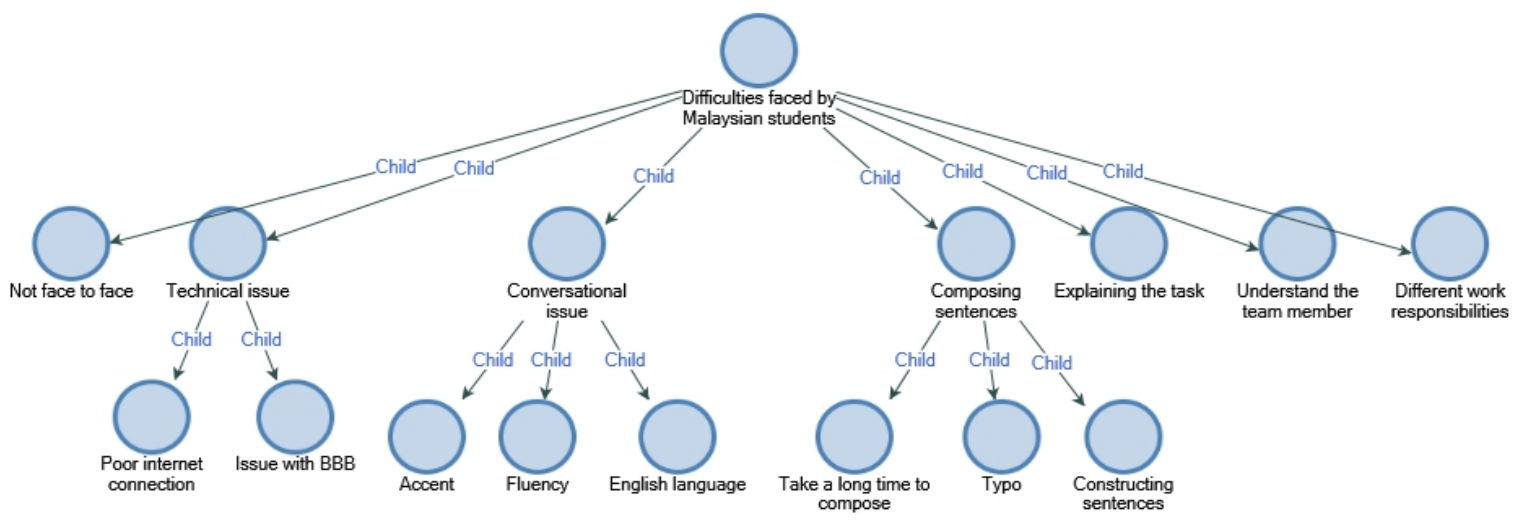

Figure 2. Difficulties experienced during the live session

The major difficulty involved conversational issues related to UK students' accents. The following respondents revealed problems in understanding the heavy accent of their UK team members.

"The first difficulty that I feel is their accent because we all know that even we are just said, that even we talk in English but not the original accent from theirs." (R2)

"The second one [difficulty] is obviously their accent, they speak very fast with a good accent of British so it is quite hard for me because I am not familiar with English with that accent.” (R3)

"When it comes to this project, I can tell that the challenge is the first language English, so they speak more fluent and fast and with their accent, actually it is catchy and hard to understand." (R4)

Another difficulty was work responsibilities among the team members. R5 voiced the misunderstanding between students in completing tasks, while R6 highlighted the lack of cooperation with regards to the division of responsibilities among team members.

"When doing group assignment, in our understanding, we have to do this and that, but in their [UK students'] understanding, they understand differently. For example, when they show their reports, their reports and our reports are a little bit different in terms of the format." (R5)

"So, when we dividing the task, they ask us to do the conclusion, and so on. But we didn't agree with them. So, I think cooperation and agreement are difficulties." (R6)

Technological glitches were another difficulty which added to the challenges experienced by the participants. Respondents R3, R6 and R8 disclosed the technological problems in using BBB during cross-cultural online collaborative activities.

\begin{abstract}
"Based on the e-learning also, when the speaker sounds not good, and then we cannot hear the other side [UK students], and then the echo and the wave, so when we have the mic on together, we cannot manage which mic we want to turn on.” (R3)

"The difficulties while doing this project actually is, I have difficulty to speak through the BBB platform. It is because my speaker is not clear to hear from the other side, and the other side does not hear my voice. So, this is difficult for me to speak." (R6)

“During the live session, we don't have any chance to talk with them [UK students], because the first live session, the server is not stable. So noisy, so we can't hear them, and for the second live session, we also have accounted problem too, because my partner in the UK, David, he has problem with the audio.” (R8)
\end{abstract}

Some respondents reported the challenging experience in structuring sentences during the interactions. They took a long time to compose their sentences, struggled to construct those sentences, made typographical errors when in the chat room and encountered difficulty in understanding and explaining the task to other team members. Failure to 'see' their team members' facial expressions when speaking added to the problem as they were unable to gauge the words spoken by their teammates during the conversations.

\section{Strategies Adopted when Communicating with Native English Speakers}

The participants adopted several strategies to optimize communication with native speakers during the live sessions. Figure 3 depicts the ten different strategies used by the students namely; writing down the phrases or words, electing a team leader, communicating through social media i.e. WhatsApp. 


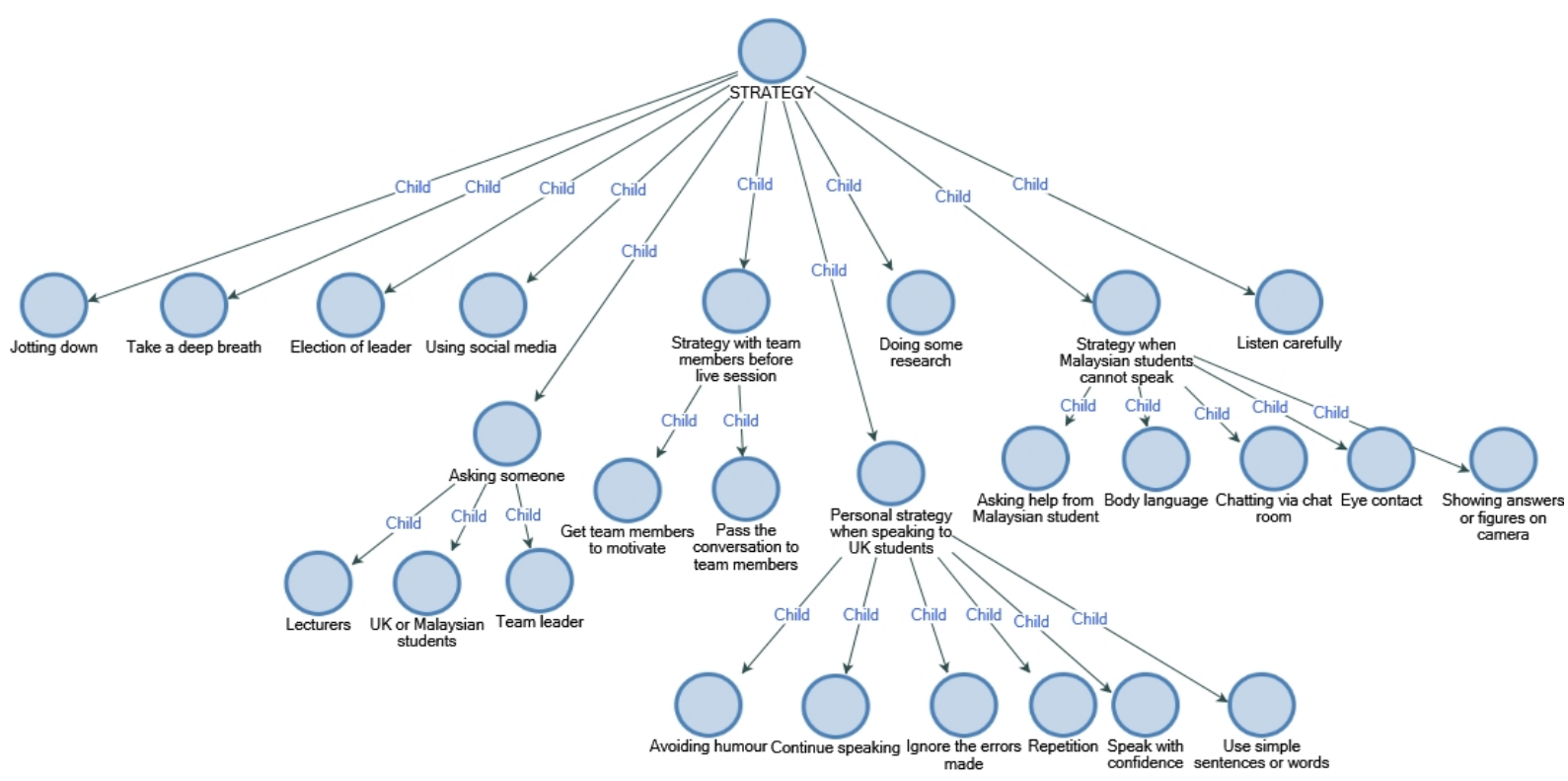

Figure 3. Strategies adopted by Malaysian students during the live sessions

Technical problems i.e. inability to communicate using the video element caused the participants to opt for the chat room in BBB web-conferencing system. The respondents below highlighted their typing strategy in the chat room:

"Strategies that I use... in Big Blue Button applet there is a chat setting so, maybe we can spell out what we want to say." (R2)

"When I make errors, I will type back in the chat setting what I want to re-correct (R3).

My strategy is, I do not really speak when I want to describe something... I'm more on type what I want to explain the task.” (R5)

"The communication around with us is not very clear through the speaker, so we have a strategy, which is we write, we rewrite the things we want to explain to them." (R6)

“If they don't understand what I'm trying to say, or speak, I used the chatting room to express my explanation. So, I think they can understand more when we write instead of [when] we speak.” (R7)

The respondents also adopted the following strategies in maintaining the conversations amid the technological glitches; trying to proceed with the conversation despite the technical problem, ignoring grammar mistakes or errors, repeating words or phrases, speaking with confidence, and using simple or short sentences when conversing. There were also instances when the respondents struggled to express the right words or sentences during the interactions. Below are their strategies;

"As we know that we all are in a group, so maybe if I don't get what they want to say, maybe I'm getting nervous, so I will pass to my members to handle the problem and maybe because we are Malay, so maybe they understand what I just want to say.” (R2)

"I will ask my lecturer, Sir Wan, what do they really want... and then when the live session begins, I will ask the UK students whether they know what the task is given. If they do not know, so I will explain to them what the task. And then I will ask the leader to divide the task.” (R3)

"I will speak whatever I want, it doesn't matter if it right or wrong, I just speak with confidence. Because when you talk in confidence, people don't realize what is mistakes we actually did.” (R4)

"When I did some error while speaking, I just pass through and I just like 'okay', and if I have a mistake while speaking, I just be confident and try to talk whatever I want to talk. I don't care about the grammar. So, I think that is the way on how to overcome this problem.” (R6)

"Strategies I use is eye contact, body language, and try to use simple words, to make them understand what I'm trying to say.” (R7)

\section{Experience after the Collaborative Online Activities}

This section presents the students' feelings after participating in the live sessions. The analysis of the interview data indicated that students expressed both positive and negative feelings as illustrated in Figure 4. 


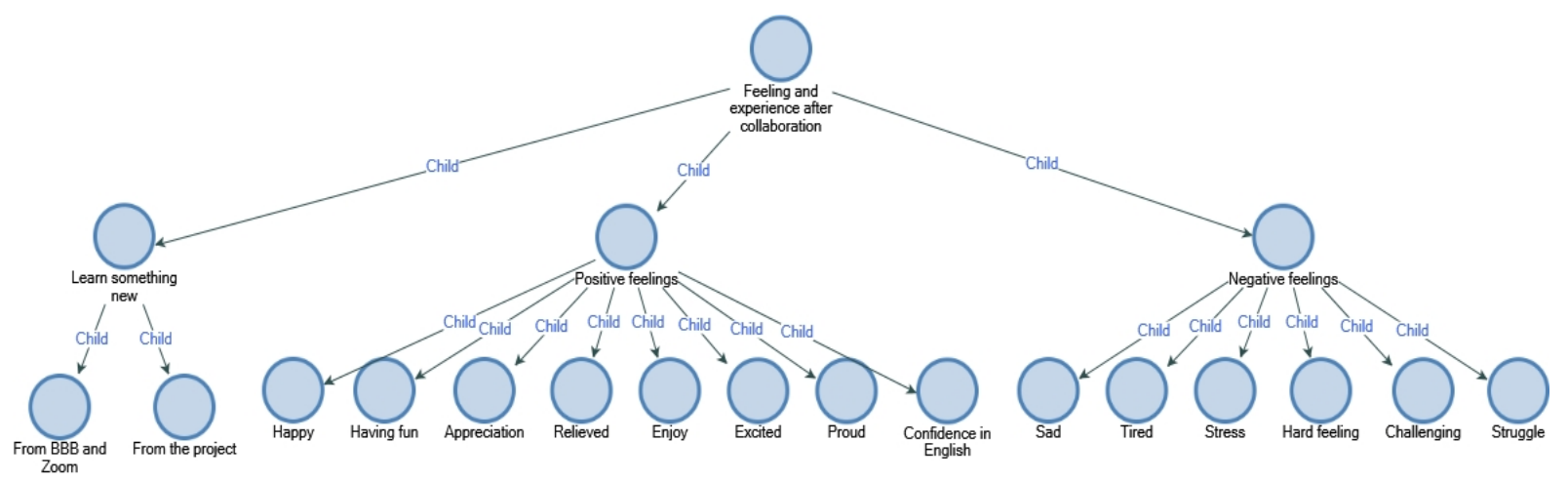

Figure 4. Feelings after the live sessions

The respondents' positive feelings were recorded below: "So glad had join this project. I hope to have another opportunity like this because for me, it can help students to expose and approach outsiders with high confidence level.” (R4)

"I learned a very sophisticated and very useful learning tool for the future. I will share with other friends about BigBlueButton. For me, this is an application very useful to all people. Maybe one day, when I become a teacher, I can use this application when I am not around in a school or can help students to revise, which is only use this application to see each other.” (R5)

"At the same time, the BigBlueButton app is very awesome and advanced for me, as I couldn't use this kind of application before this. My feeling while using this apps such like "Wahhh", it is so powerful. For me, the person who created this application was awesome and adorable. Then, this application helps us a lot to finish the task given. By using this application, it is much easier for me to collaborate with the people who are far away from me.” (R6)

"It is hard to understand them since they [UK students] are English speakers, so I had a struggle a bit in completing my work together [with] the tasks in this project.” (R6)

"I must say I did enjoy it. I have learned quite a lot about stellar evolution, thanks to this project. However, due to my busy schedule, it was quite hard for me to finish the tasks given on time, which actually has given me an insight about my time management so that's all on me.” (R7)

Nonetheless, the participants also voiced some negative feelings after their collaborative activities which include fatigue - probably because the 2-hour live sessions required very focused attention as they were involved in several non-stop activities from $5 \mathrm{pm}-7 \mathrm{pm}$, stress - having to complete the tasks in a very limited time and hard feeling due to the technological glitches which had affected their team's focus and performance.

\section{Conclusions}

This paper presents the results of a cross-cultural analysis by exploring the difficulties, strategies, and feelings experienced by Malaysian undergraduate students during collaborative online activities with native English speakers. Results from the qualitative analysis reported the positive sentiments of Malaysian students on online collaborative activities. This has increased their self-esteem to a certain degree, particularly for those who have never spoken with a native English speaker prior to the engagement of the project. In addressing the communication problems that occurred during the synchronous activities with the UK students, they applied multiple communication strategies. With regard to this, Mimi Nahariah et. al (2020) revealed that the perception of the discrepancies between cultures influences how people of different cultural backgrounds interact. This paper has interestingly captured such inter-cultural differences through the online communication exchanges. The authors also stressed that such inter-cultural communication performance is determined by the flexibility of the interlocutors and behavioural adaptation of each other's cultural context.

During the online activities, Malaysian students faced difficulties predominantly due to the natives' accent and own limited English vocabulary. The second challenge involved technical issues posed by the online platform the $\mathrm{BBB}$ web conferencing system as well as a poor internet connection. Hence, the respondents adopted a few strategies to tackle these technological issues namely chatting and jotting down words/phrases when they were unsure of the pronunciation or unable to communicate due to the technological glitches.

There appears to be some strategic resemblance between the strategies adopted by Malaysian students with Dörnyei and Scott's (1997) taxonomy of communicative strategies. A general pattern of indirect and interactional strategies was evident during the interactions. The participants formulated indirect strategies in achieving mutual understanding and keeping the dialogues open by repeating words/phrases. They also continued the discourse by 
ignoring their grammatical errors despite consciously realizing that their sentences may or may not be understood by the UK team members. Besides, the interactional strategy was performed through their appeal of help from fellow Malaysian team members, team leaders, and instructors. Such requests were sought when they confronted problems searching for suitable words to say, consumed too much time in constructing sentences, failed to translate words from Malay to English, spelled certain words wrongly, faced problems explaining the tasks due to limited astronomical knowledge or when they requested further explanations on specific individual tasks.

Those strategies were adopted in solving the communication problems they encountered during the live sessions. The students were concerned with their performance and were positive that the project could enhance their communication skills as well as improve their confidence levels when communicating in English. Independent self-study, engaging in research about UK students' culture before the live sessions, using social media as means of discussing the project after the live sessions, attentive listening and building self-confidence were important strategies adopted in the project.

Garrison's (2019) community of inquiry namely social presence and cognitive presence were significantly addressed in the research project. The social presence was obvious when a climate of trust was established namely the election of the group leader and the effort taken in understanding the different work responsibilities of each member. Similarly, multiple instances of cognitive presence were evident when students engage and collaborate with their peers on academic matters; 1) the students' effort to connect with the team members, both locally and abroad via social media application i.e WhatsApp in completing the tasks; 2) encouragement and mental preparations before the live sessions for the difficult task ahead; 3) helping each other during the interactions with the native speakers. This paper also supports the distinction between students' use of synchronous and asynchronous communication tool in online group activities, as highlighted by Hanan and Martin (2017).

The findings of this study strongly advocate that the respondents were mostly positive in their communication with the native speakers and believed in the benefits of the process. Even though several participants reported negative feelings when communicating, the positive attitudes and the students' willingness to engage and learn with the native speakers far outweighed the negative thoughts. Despite the technical glitches during both live sessions, Malaysian students were positive in their acceptance and attitudes towards using the BBB application, evidence which suggests that web-conferencing tools hold great potential and alternatives for language teaching in the Malaysian context.

Despite involving only a small sample of undergraduate students from Malaysia, the results provided several findings for future studies in the field of cross-cultural communication and collaborative online learning. Malaysian students were positive about online collaborative learning and concurred that such activities could help develop cooperation, enhance teamwork abilities, foster individual independence and promote cross-cultural awareness among students from both Malaysia and the UK. Such programs also trigger innovative ideas on how to tackle difficult situations, solve communication problems as well as improve students' communication skills, self-awareness, and teamwork efforts.

\section{Acknowledgment}

The authors wish to gratefully acknowledge the Ministry of Education Malaysia for funding this project under the Newton Ungku Omar Fund, Vote no. R.K130000.7341.4B296, as well as Universiti Teknologi Malaysia and Universiti Kebangsaan Malaysia for overseeing the management of the research project.

\section{REFERENCES}

[1] Abrar, M., Mukminin, A., Habibi, A., Asyrafi F., Makmur M. \& Marzulina, L. (2018). "If our English isn’t a language, what is it?” Indonesia EFL Students Teachers' Challenges Speaking English. The Qualitative Report, 1(6), 129-145.

[2] Baruah, J. \& Paulus, P. B. (2018). Collaborative Creativity and Innovation in Education. Creativity Theory and Action in Education, 3, 155-177.

[3] Braun, V. \& Clarke, V. (2006). Using Thematic Analysis in Psychology. Qualitative Research in Psychology, 12(1), 528.

[4] Canale, M. \& Swain, M. (1980). Theoretical Bases of Communicative Approaches to Second Language Teaching and Testing. Applied Linguistics, 1(1), 1-47.

[5] Corder, S. P. (1981). Error analysis and interlanguage. Oxford: Oxford University Press

[6] Dörnyei, Z. \& Scott, M. L. (1997). Communication Strategies in a Second Language: Definitions and Taxonomies. Language Learning, 47:1, 173-210.

[7] Faerch, C \& Kasper, G. (1980). Processes and Strategies in Foreign Language Learning and Communication. Interlanguage Studies Bulletin Utrecht, 5, 47-118.

[8] Faerch, C \& Kasper, G. (1984). Two Ways of Defining Communication Strategies. Language Learning, 34(1), 45-63.

[9] Garrison, D. (2019). Online Community of Inquiry Review: Social, Cognitive, and Teaching Presence Issues. Online Learning, 11(1), 61-72. 
[10] Hadwin, A.F., Bakhtiar, A. \& Miller, M. (2018). Challenges in online collaboration: effects of scripting shared task perceptions. Intern. J. Compt.-Support. Collab. Learn, 13, 301-329.

[11] Hammond, M. (2017). Online collaboration and cooperation: The recurring importance of evidence, rationale and viability. Educ Inf Technol, 22, 1005-1024.

[12] Hanan Khalil and Martin Ebner (2017). Using Electronic Communication Tools in Online Group Activities to Develop Collaborative Learning Skills. Universal Journal of Educational Research, 5(4), 529 - 536. DOI: 10.13189/ujer.2017.050401.

[13] Haythornthwaite, C. (2019). Facilitating Collaboration in Online Learning. Online Learning, 10(1), 7-24.

[14] Kumi-Yeboah, A., Dogbey, J. \& Yuan, G. (2017). Online Collaborative Learning Activities: The Perception of Culturally Diverse Graduate Students. Online Learning, 2(4), 5-28.

[15] Miles, M. B. \& Huberman, A. M. (1994). Qualitative Data Analysis: An Expanded Sourcebook. Beverly Hills.

[16] Mimi Nahariah Azwani Mohamed, Nurizah Md Ngadiran, Nurzarina Abd Samad, Nor Fadhilah Ahmad Powzi (2020). English Language Learning Beyond the Borders: Constructing E-Collaborative Learning between Students of Different Regions. Universal Journal of Educational Research, 8(5A), 108 - $113 . \quad$ DOI: 10.13189/ujer.2020.081916.

[17] Mukminin, A., Masbirorotni, M., Noprival, N., Sutarno, S., Arif, N. \& Maimunah. (2015). EFL Speaking Anxiety among Senior High School Students and Policy Recommendations. Journal of Education and Learning, 9(3), 217-225.

[18] Nunan, D. \& Bailey, K. M. (2009). Exploring Second Language Classroom Research: A Comprehensive Guide. Boston USA: Heinle CENCAGE Learning.

[19] Oliveira, I., Tinoca, L \& Pereira, A. (2011). Online group work patterns: How to promote a successful collaboration. Computers \& Education, 57(1), 1348-1357.

[20] Richards, L. (2005). Handling Qualitative Data. Sage Publications Limited.

[21] Romadlon, F. N. (2016). Communication Strategies in the Conversations Between Indonesian University Students and A Native Speaker. Jurnal Vision, 5(1), 5-26.

[22] Selinker, L. (1972). Interlanguage. IRAL, 10, 209-230.

[23] Setlock, L. D., Fussell, S. R. \& Neuwirth, C. (2004). Taking It Out of Context: Collaborating Within and Across Cultures in Face-to-Face Setting and via Instant Messaging. Proceeding of the 2004 ACM Conference on Computer supported Cooperative Work, 604-613.

[24] Shumin, K. (2002). Factors to Consider: Developing Adult EFL Students' Speaking Abilities. Methodology in Language Teaching: An Anthology of Current Practice, 12, 204-211.

[25] Singh, M. K. M. (2016). An Emic Perspective on Academic Writing Difficulties among International Graduate Students in Malaysia. Journal of Language Studies, 16(3), 83-97.

[26] Tarone, E. (1980). Communication strategies, foreigner talk and repair in interlanguage. Language Learning, 30, 417-431.

[27] Teng, L. Y. W. (2007). Collaborating and Communicating Online: A Cross Bordered Intercultural Project between Taiwan and the US. Journal of Intercultural Communication, 13, 8-18.

[28] Wang I-Ching, Ahn, J.N., Kim, H.J., and Lin-Siegler, X. (2017). Why Do International Students Avoid Communicating with Americans? Journal of International Students, 7(3), 555-580.

[29] Yang, J., Kinshuk, H. Yu, Chen, S. J. \& Huang, R. (2014). Strategies for Smooth and Effective Cross-Cultural Online Collaborative Learning. Educational Technology \& Society, 17(3), 208-221. 